\title{
CD226 ligation protects against EAE by promoting IL-10 expression via regulation of $\mathrm{CD}^{+} \mathrm{T}$ cell differentiation
}

\author{
Rong Zhang ${ }^{1,2, *}$, Hanyu Zeng ${ }^{1, *}$, Yun Zhang ${ }^{1, *}$, Kun Chen ${ }^{3}$, Chunmei Zhang ${ }^{1}$, Chaojun \\ Song $^{1}$, Liang Fang ${ }^{1}$, Zhuwei Xu ${ }^{1}$, Kun Yang ${ }^{1}$, Boquan Jin ${ }^{1}$, Qintao Wang ${ }^{2}$ and Lihua \\ Chen $^{1}$ \\ ${ }^{1}$ Department of Immunology, The Fourth Military Medical University, Xi'an, Shaanxi, P.R. China \\ ${ }^{2}$ State Key Laboratory of Military Stomatology, Department of Periodontology, School of Stomatology, The Fourth Military \\ Medical University, Xi'an, Shaanxi, P.R. China \\ ${ }^{3}$ Department of Neurobiology, The Fourth Military Medical University, Xi'an, Shaanxi, P.R. China \\ * These authors have contributed equally to this work \\ Correspondence to: Lihua Chen, email: chenlh@fmmu.edu.cn \\ Qintao Wang, email: watzym@fmmu.edu.cn \\ Keywords: CD226, CD4+ T cells, IL-10, EAE, iTreg, Immunology and Microbiology Section, Immune response, Immunity \\ Received: August 19, $2015 \quad$ Accepted: January 29, $2016 \quad$ Published: March 01, 2016
}

\section{ABSTRACT}

Treatment targeting CD226 can ameliorate experimental autoimmune encephalomyelitis (EAE), the widely accepted model of MS. However, the mechanisms still need to be elucidated. Here we showed that CD226 blockage by anti-CD226 blocking mAb LeoA1 efficiently promoted IL-10 production in human peripheral blood monocytes (PBMC) or in mixed lymphocyte culture (MLC) system, significantly induced the $\mathrm{CD4}^{+} \mathrm{IL}^{-10^{+}} \mathrm{T}$ cell differentiation while suppressing the generation of Th1 and Th17. Furthermore, CD226 pAb administration in vivo reduced the onset of EAE in mice by promoting IL-10 production and regulating $T$ cell differentiation. Concomitantly, the onset and severity of EAE were reduced and the serum IL-10 expression levels were increased in CD226 knockout mice than that in control mice when both received EAE induction. These novel findings confirmed that CD226 played a pivotal role in mediating autoimmune diseases such as EAE. Furthermore, to our knowledge, we show for the first time that IL-10 is an important contributor in the inhibitory effects of CD226 ligation on EAE.

\section{INTRODUCTION}

$\mathrm{CD}^{+} \mathrm{T}$ lymphocytes play an important role in regulating host immune responses as well as inflammatory and autoimmune diseases. As an important influencing factor, Th subsets differentiation disorders have been shown to be highly associated with the pathogenesis and progression of EAE [1]. Specifically, the proinflammatory IFN- $\gamma$-producing Th1 cells and IL-17 producing Th17 cells could be used in EAE induction, with different pathological phenotypes [1, 2]. Moreover, immune suppressive agent dihydroartemisinin was proved to be effective in ameliorating EAE by suppressing Th cell function, particularly by abolishing Th17 differentiation [3]. Interleukin-10 (IL-10), a cytokine with antiinflammatory properties, plays a crucial role in preventing various inflammatory pathologies especially in tumor and autoimmune diseases $[4,5]$. Administration of IL10 has been demonstrated to suppress EAE under some conditions $[6,7]$. Also, high IL-10 expression level within the central nervous system is considered to be important for the initiation of recovery from EAE [8]. The mechanism may lie in the inhibition of $\mathrm{T}$ cell subsets maturation and autoreactive $\mathrm{CD}^{+} \mathrm{T}$ cell expansion in the central nervous system (CNS). Meanwhile, IL-10deficient mice develop more severe EAE than wild-type (WT) mice [9], thus demonstrating its beneficial effects on the pathogenesis of EAE.

CD226, also known as DNAX accessory molecule-1 (DNAM-1) or platelet and T cell activation antigen 1 (PTA1), is involved in various pathological processes including autoimmune diseases, tumor, transplantation rejection and virus infection diseases [10,11]. As for the relationship between CD226 and EAE or MS, it was 
reported that anti-CD226 treatment delayed the onset and reduced the severity of Th1-mediated EAE [12]. Moreover, neutralizing anti-CD226 mAb decreased T cell activation and inhibited proliferation of $\mathrm{CD}^{+} \mathrm{T}$ cell isolated from untreated patients with relapsing remitting MS [13]. However, the mechanisms underlying how CD226 exerts its impact on EAE still needs to be further elucidated.

IL-10 is an important mediator which exerts multiple immunosuppressive actions, including modulation of APCs [14], inhibition of T cell proliferation [15], and maintaining the function/stability of established Tregs $[16,17]$. Our previous studies in nearly 2000 showed that CD226 blocking mAb LeoA1 could efficiently promote the production of IL-10 in human PBMC and MLC culture systems (data not published). Given the important role of Th subsets and IL-10 in EAE, we investigated whether anti-CD226 Ab could ameliorate EAE via the alteration of IL-10 expression levels and the differentiation of Th subsets.

\section{RESULTS}

\section{CD226 ligation promotes IL-10 production in human PBMC and MLC culture supernatants}

To assess the effect of the CD226 ligation on the cytokine secretion profile in human PBMC and MLC systems, we measured the IFN- $\gamma$, TNF- $\alpha$, IL- 12 , IL17, IL-23, IL-10, IL-2 and IL-4 expression levels in the supernatants of PBMC and MLC systems at different time points. We found that CD226 mAb LeoA1 decreased IFN- $\gamma$, TNF- $\alpha$, IL-12 and IL-23 but increased IL-10 secretion in both systems and only decreased IL-2 and IL-17 expression levels in MLC system. However, the production of IL-4, which is predominantly secreted by Th2, almost remained the same in both systems (Figure $1 \mathrm{~A}$ and $1 \mathrm{~B})$.

Then we analyzed whether the regulatory effect of LeoA1 was related to time course. By making a ratio of four representative cytokine expression levels between

A
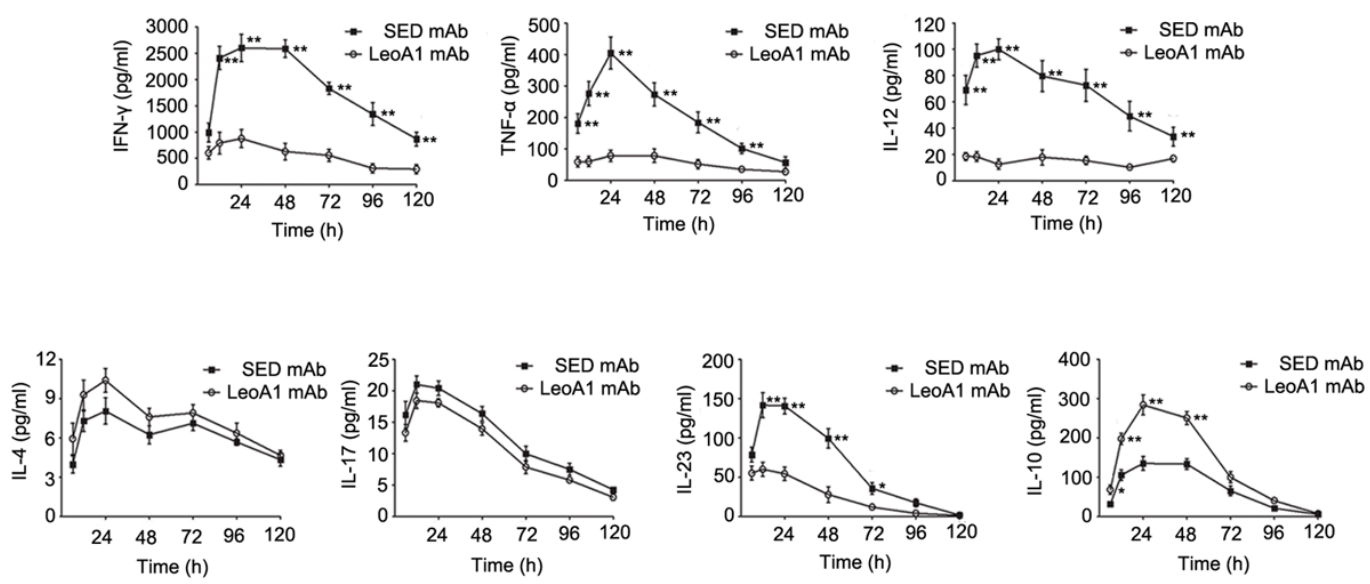

B
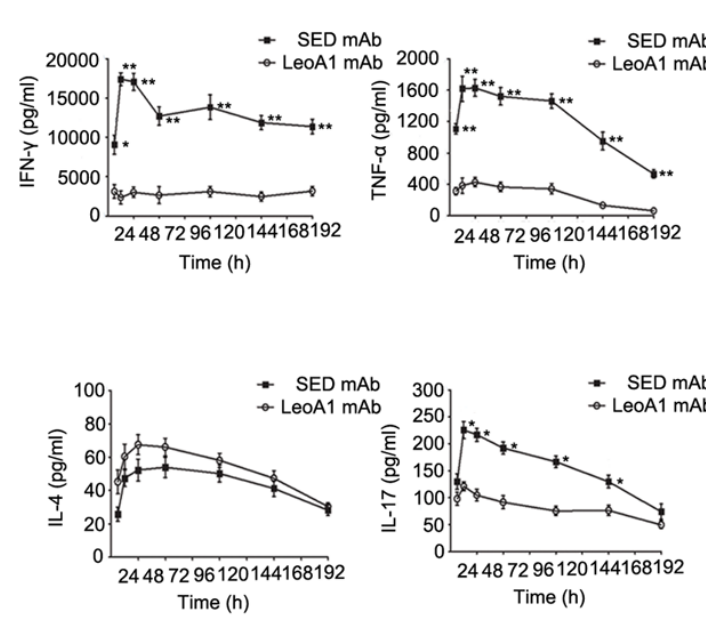
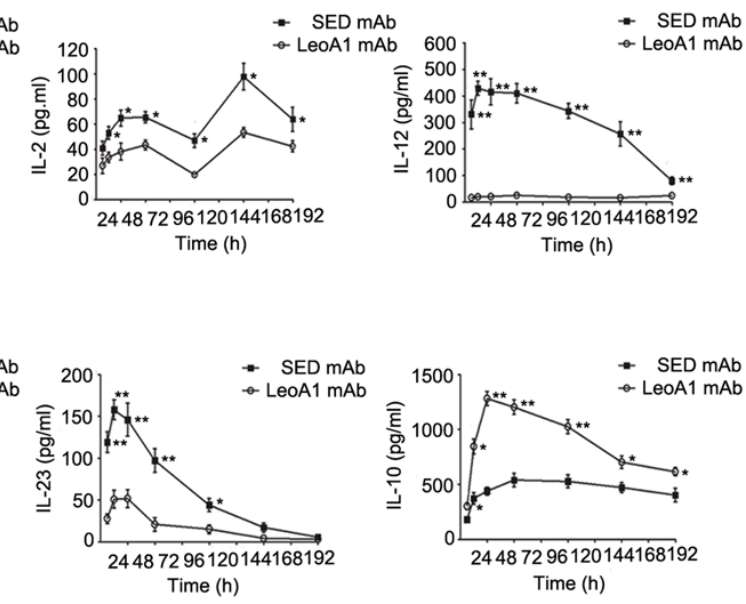
C
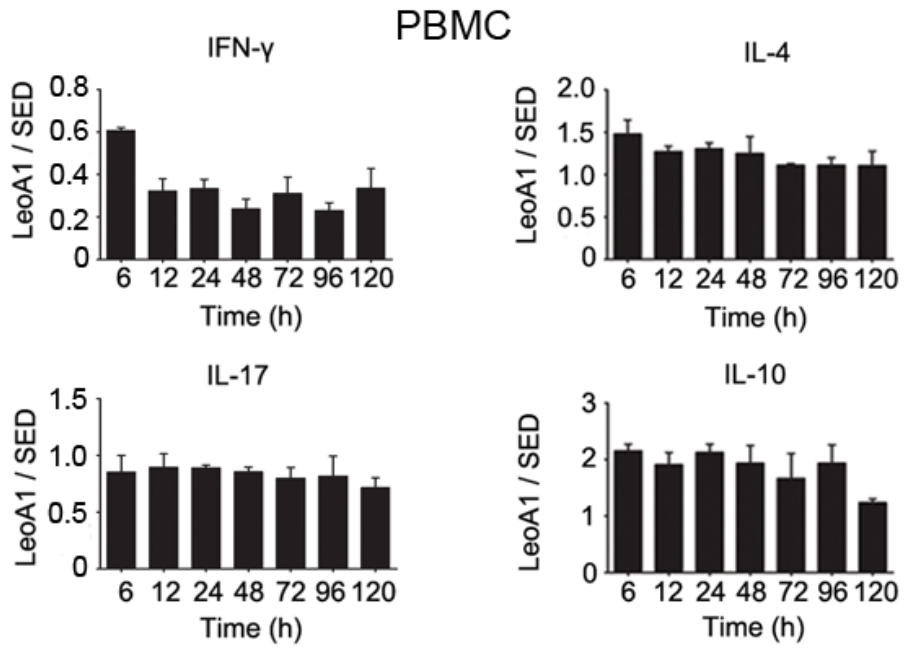

D

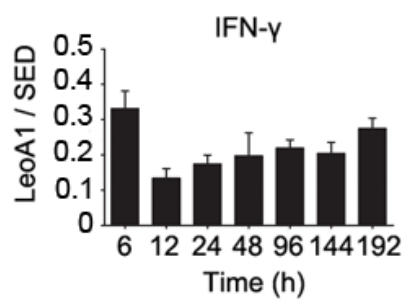

MLC
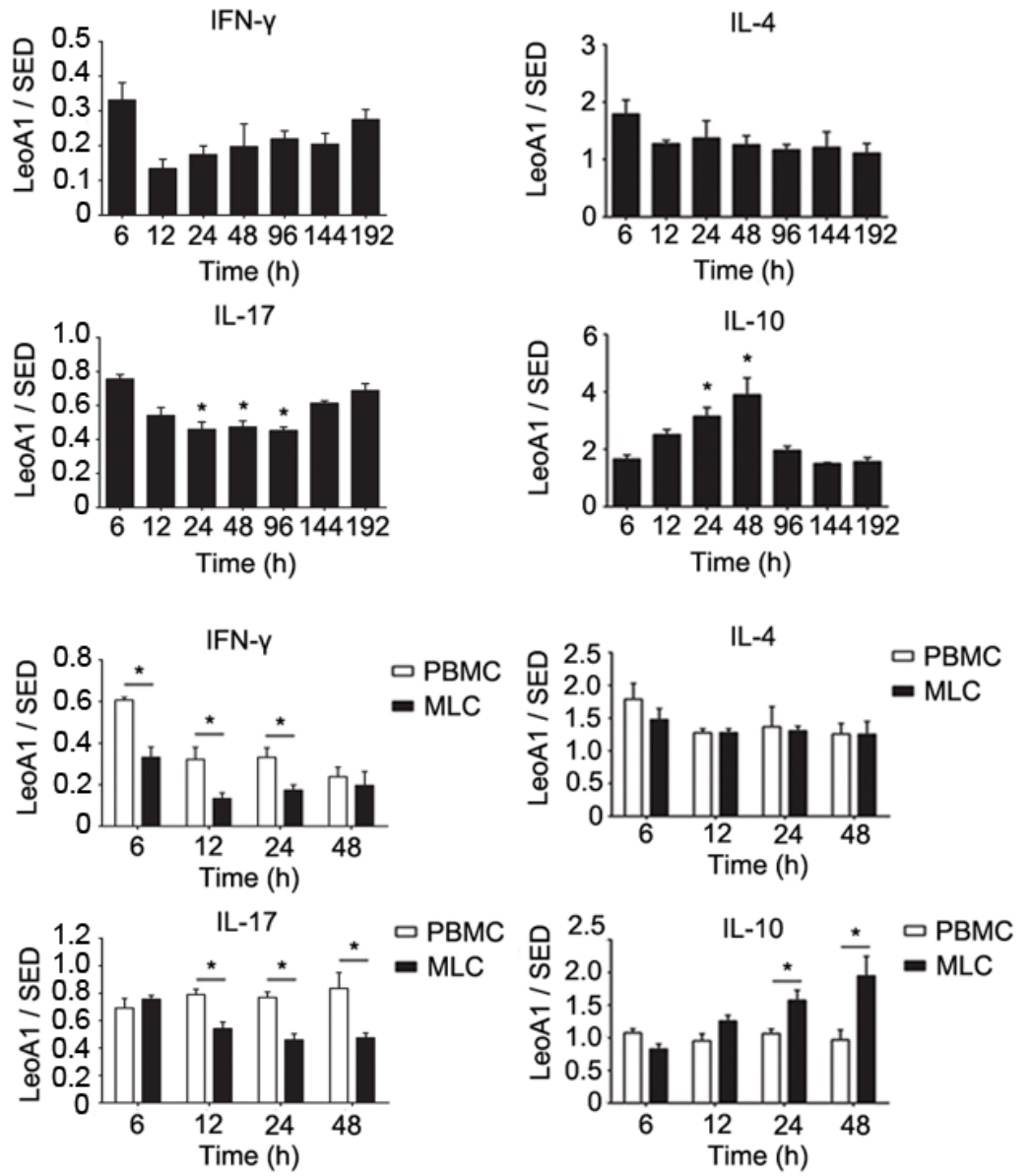

Figure 1: CD226 mAb LeoA1 upregulates IL-10 production in human PBMC and MLC culture supernatants. A. Human PBMC were isolated from peripheral blood and cultured under the treatment of LeoAl and SED mAb (negative control) for the indicated periods of time. The production of $\mathrm{CD}^{+} \mathrm{T}$ cell subsets associated cytokines in the supernatants were assessed by ELISA. B. The same experiments were repeated under the MLC system containing Daudi and PBMC as the stimulator cells and responding cells respectively for the indicated time. The ratio between the typical $\mathrm{CD} 4^{+} \mathrm{T}$ cells associated cytokines production of the two groups obtained from experiments described in (A and B) was calculated in PBMC C. and MLC D. systems respectively. ${ }^{*} P<0.05$ by comparison to all the other bars without *. E. As described in (C and D), the ratio was compared between the PBMC and MLC systems at the four coincident time points. Data are representative of at least three independent experiments. Error bars denote SEM (A and B) or SD (C-E). * $P<0.05$. $* * P<0.01$. 
the LeoA1 and SED groups, we found that LeoA1 exerted the regulatory function to a stable extent without being affected by time in the PBMC system (Figure 1C). However, the expression levels of IL-17 and IL-10, referring to the MLC system, were altered much more significantly from $24 \mathrm{~h}$ to $48 \mathrm{~h}$ (Figure 1D). Furthermore, when the two culture systems were compared, LeoA1 performed a much fiercer effect on the three cytokine production (IFN- $\gamma$, IL-17, IL-10) in the MLC system and the most obvious elevated IL-10 expression level in MLC compared with that in PBMC was at $48 \mathrm{~h}$ after the treatment. (Figure 1E)

\section{CD226 ligation up-regulates the frequencies of $\mathrm{CD4}^{+} \mathrm{IL}^{-10^{+}} \mathrm{T}$ cells in human PBMC and MLC culture systems}

Considering the above results that CD226 ligation could significantly up-regulate IL-10 expression levels and IL-10 plays a crucial role in preventing inflammatory and autoimmune pathologies, we next explored whether
CD226 mAb could promote the differentiation of IL-10 ${ }^{+}$ immunocytes in PBMC. Flow cytometry analysis showed that in MLC system (Daudi as APC), after 24h treatment, LeoA1 had no obvious effect on IL- $10^{+}$proportion of DCs, macrophages, NK cells and B cells (Supplemental Figure 1), which can produce different amount of IL-10 [18]. However, the frequencies of IL-10 secreting CD4 ${ }^{+} \mathrm{T}$ cells were efficiently elevated from $0.134 \%$ to $0.750 \%$ and from $0.152 \%$ to $1.330 \%$ after LeoA 1 treatment in PBMC (Figure 2A and 2B) and MLC (Figure 2C and 2D) system respectively. These data suggested that CD226 ligation promoted $\mathrm{CD} 4^{+} \mathrm{IL}-10^{+} \mathrm{T}$ cell differentiation.

\section{CD226 ligation inhibits the production of Th1/ Th17 associated genes and cytokines while promoting the iTreg associated ones}

Considering the complexity of PBMC and MLC systems, to address the functional role of CD226 in cytokine production of $\mathrm{CD}^{+} \mathrm{T}$ cells, we purified human $\mathrm{CD}^{+} \mathrm{T}$ cells which were activated with anti-CD3 and

A
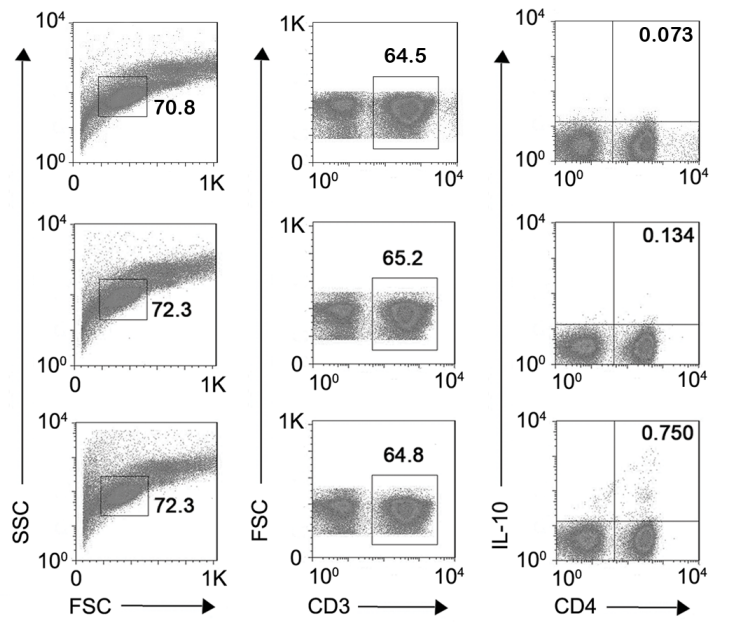

C

B
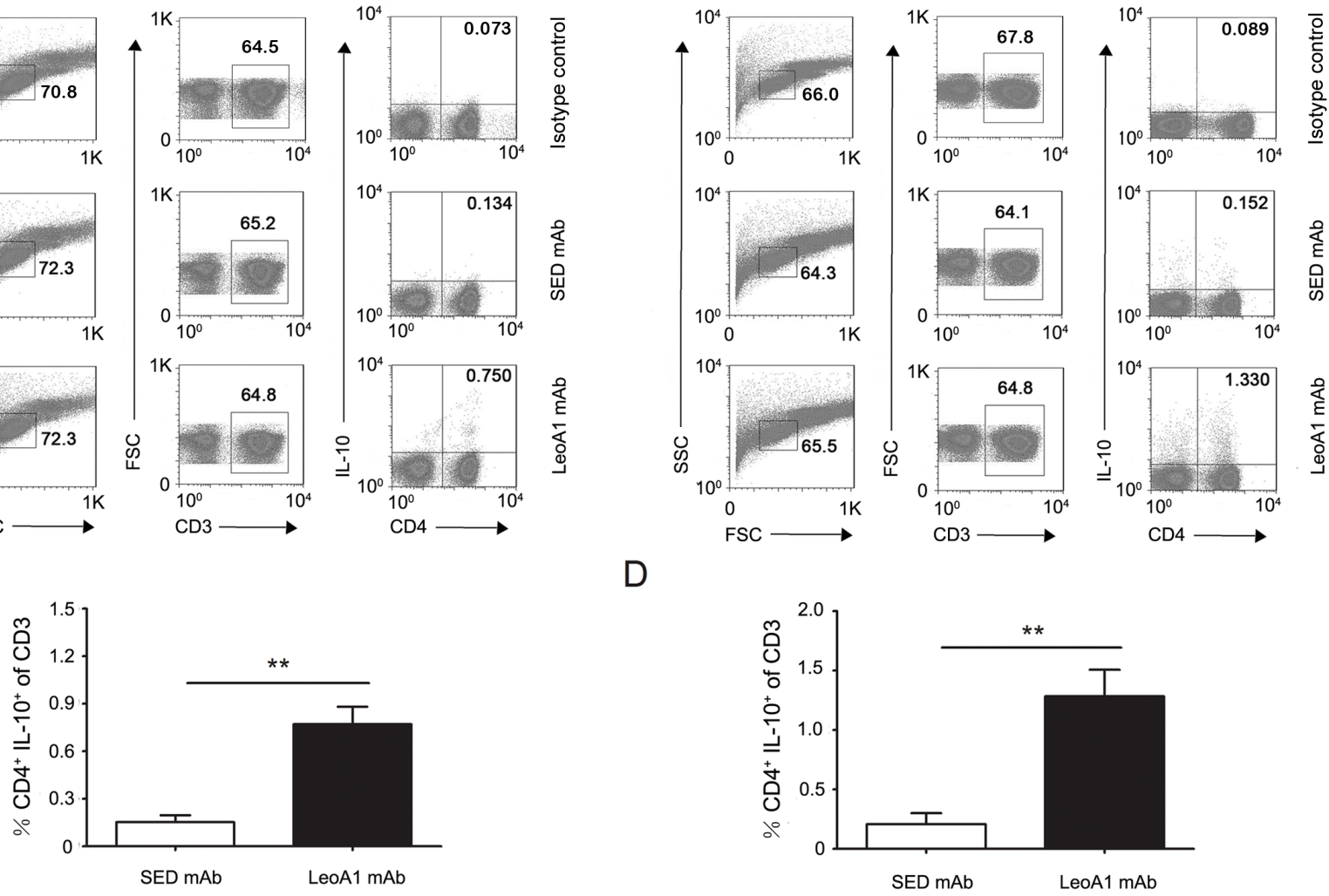

Figure 2: CD226 mAb LeoA1 promotes the differentiation of $\mathbf{C D}^{+} \mathbf{I L}_{-10} \mathbf{T}^{+} \mathbf{T}$ cells. A. Human PBMC were cultured with LeoA1 or SED mAb for $24 \mathrm{~h}$ and submitted to flow cytometry analysis by gating on $\mathrm{CD}^{+}$followed by surface expression of CD4 versus IL-10 and isotype control antibody intracellular staining on cells, stimulated with PMA and ionomycin for 4h in the presence of GolgiStop. Cells were stained with LIVE/DEAD Fixable Dead Cell Stain Kit before fixation to allow gating on viable cells. B. The frequencies of $\mathrm{CD}^{+} \mathrm{IL}_{-10^{+}}$in the total T cells from experiments described in (A) were compared. C. The same experiment as in (A) was duplicated under MLC system. D. The frequencies of $\mathrm{CD}^{+} \mathrm{IL}-10^{+}$in the total T cells from experiments described in (C) were compared. Data are representative of at least three independent experiments. Error bars denote SD. ${ }^{* *} P<0.01$. 
anti-CD28, then with anti-CD226 or SED mAb under Th1, Th2, Th17 or iTreg conditions for 4d. As expected, anti-CD226 mAb LeoA1 inhibited the mRNA expression of IFN- $\gamma$ and IL-17 while elevated the mRNA level of IL-10 (Figure 3A). Meanwhile, IFN- $\gamma$ and IL-17 secretion levels were significantly decreased while IL10 expression level was obviously elevated in the LeoA1 treatment group (Figure 3B). However, there is little difference on Th2 associated cytokine IL-4 expression on both mRNA and protein levels (Figure $3 \mathrm{~A}$ and $3 \mathrm{~B}$ ). Furthermore, LeoA1 treated cells expressed lower levels of T-bet and ROR $\gamma$ t (the master transcription factors for Th1 and Th17 respectively), higher level of Foxp3 (the master transcription factor for iTreg) and an unchanged level of GATA3 (key transcription factor for Th2) (Figure 3C). Collectively, our data strongly suggested that CD226 promoted iTreg differentiation while inhibited Th1/Th17 generation.

\section{CD226 pAb treatment in vivo reduces EAE susceptibility and severity}

The findings that CD226 ligation could promote IL10 cytokine secretion led us to further investigate whether
CD226 is involved in the development of autoimmune diseases such as EAE, a murine model for human multiple sclerosis, which has been proved to be regulated by Th1/ Th17 as well as Tregs [19-21]. After administrated every other day during the first $8 \mathrm{~d}$ of EAE elicitation, CD226 $\mathrm{pAb}$ efficiently reduced the incidence and postponed the median incidence time of EAE onset (Figure 4A and 4B). In addition, the clinical scores of CD226 pAb treated EAE mice were much lower than that of mice treated with control $\mathrm{Ab}$ (Figure 4C), suggesting that administration of CD226 pAb effectively reduced EAE susceptibility and severity. These results were consistent with the findings that anti-CD226 treatment delayed the onset of EAE in mice and inhibited the activation and proliferation of $\mathrm{CD}^{+}$ $\mathrm{T}$ cells isolated from MS patients $[12,13]$.

Histopathological assessment of representative lumbar spinal cord sections demonstrated the potent role of $\mathrm{CD} 226 \mathrm{pAb}$ in reducing the infiltration of inflammatory cells in CNS characterized by less infiltration of parenchymal perivascular mononuclear cells in the meninges and parenchyma which is associated with demyelination compared with that in the control group (Figure 4D and 4E). Therefore, CD226 was highly related to the initiation and maintenance of EAE.

B
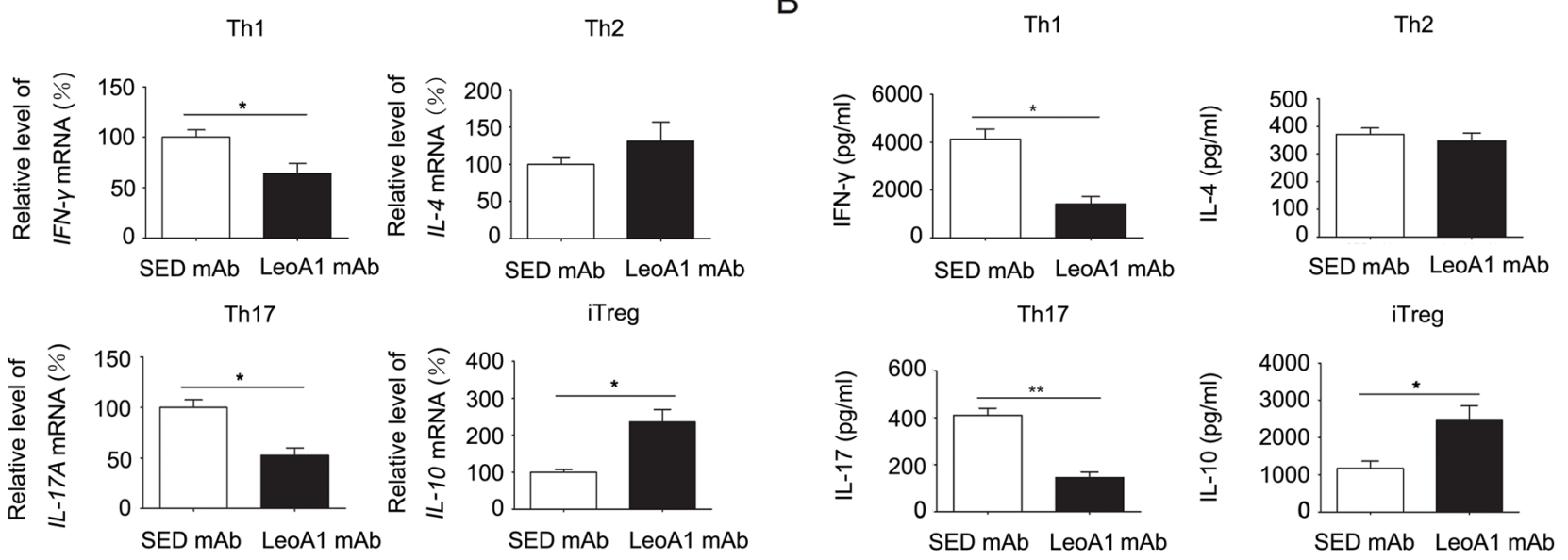

C
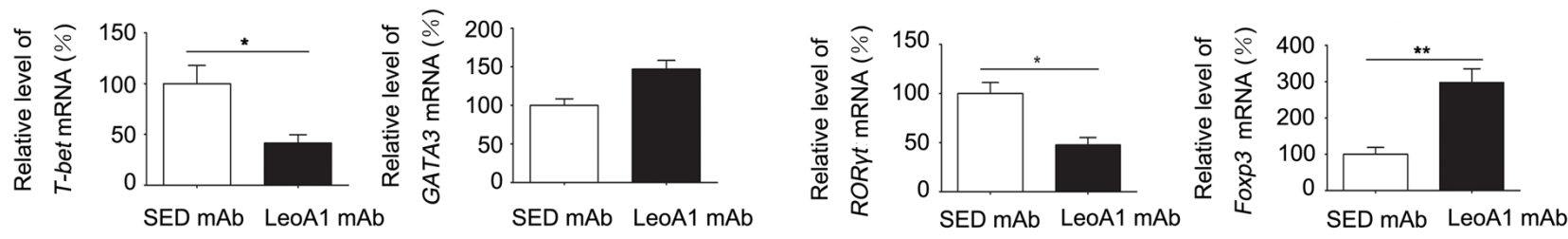

Figure 3: CD226 mAb LeoA1 inhibits the production of Th1/Th17 related genes and cytokines while promotes iTreg associated ones in human $\mathrm{CD}^{+} \mathbf{T}$ cells. A. MACS-sorted $\mathrm{CD}^{+} \mathrm{T}$ cells from human PBMC were activated with anti-CD3 and antiCD28 in the presence of LeoA1 or SED mAb under Th1, Th2, Th17 or iTreg conditions respectively for 4d. mRNA expression of IFN- $\gamma$, IL4, IL-17 and IL-10 were analyzed by quantitative real-time RT-PCR. B. Measurement of IFN- $\gamma$, IL-4, IL-17 and IL-10 in the supernatants derived from the same cultures as in (A) was quantified by ELISA. C. The gene expression of Th1, Th2, Th17, iTreg associated master transcription factors in human $\mathrm{CD}^{+} \mathrm{T}$ cells were analyzed by quantitative real-time RT-PCR undergoing the same treatment as in (A). Data are representative of at least three independent experiments. Error bars denote SEM. $* P<0.05, * * P<0.01$. 


\section{CD226 pAb promotes splenic $\mathrm{CD4}^{+}{ }^{+} \mathrm{L}_{-10}{ }^{+} \mathrm{T}$ cell differentiation in EAE mice}

Intrigued by the above observations, we further investigated the mechanisms by which CD226 affects EAE. Considering the ex vivo findings that CD226 efficiently inhibited the Th1/Th17 differentiation but promoted iTreg generation in humans, and our finding that CD226 was highly expressed on the surface of mice Th17 and Treg which played important roles in EAE pathologies (data not shown), we speculated that CD226 might be involved in mice EAE through modulating the Th cell subsets and iTreg differentiation. To confirm this hypothesis, splenocytes from the EAE mice administrated with $\mathrm{CD} 226 \mathrm{pAb}$ or control $\mathrm{Ab}$ were isolated. Th subsets and associated cytokine expression levels were assessed by intracellular cytokine staining and ELISA respectively. It was found that $\mathrm{CD} 226 \mathrm{pAb}$ treatment strongly decreased the frequency of CD4 $4^{+} \mathrm{IL}-17^{+} \mathrm{Th} 17$ while elevated that of $\mathrm{CD} 4^{+} \mathrm{IL}-10^{+} \mathrm{T}$ cells with no significant effect on the IFN- $\gamma$ producing Th1 and IL-4 producing Th2 (Figure 5A and 5B). Meanwhile, CD226 pAb treated EAE mice produced less IL-17 and more IL-10 comparing with that of control mice (Figure 5C).

To further confirm the in vivo results, mice splenocytes were isolated and added into the CD226 pAb pre-coated plate. In line with the in vivo data, CD226 pAb crosslinked mice splenocytes showed a lower frequency of $\mathrm{CD}^{+} \mathrm{IL}^{-17^{+}}$but a higher percentage of $\mathrm{CD} 4^{+} \mathrm{IL}-10^{+}$ $\mathrm{T}$ cells compared with that of the control ones (Figure 6A and 6B). ELISA results also showed the similar role of CD226 pAb in inhibiting IL-17 and promoting IL-10 secretion (Figure 6C).

\section{CD226 knockout mice show significantly better outcome of EAE accompanied by higher IL-10 expression levels}

CD226 knockout mice were used to further assess the effect of CD226 on the induction of EAE. C57BL wild type mice initially showed clinical signs of EAE on day 8 and all became sick on day 11 after EAE elicitation. In contrast, CD226 knockout mice showed clinical signs of EAE on day 11 with $40 \%$ remaining healthy till the end of our assay (Figure 7A). Similarly, the median incidence time was also markedly postponed in the CD226 knockout
A

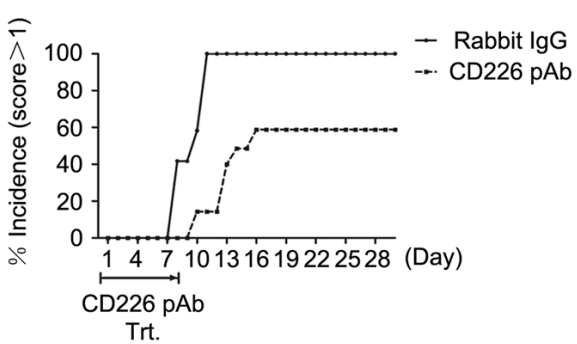

D

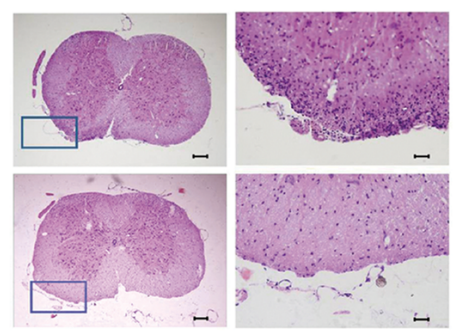

B

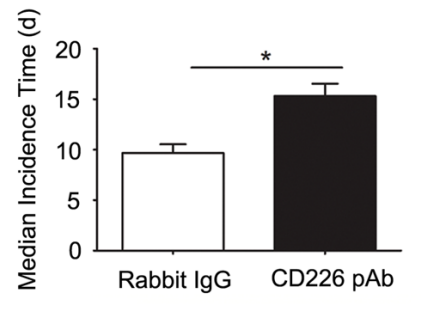

E

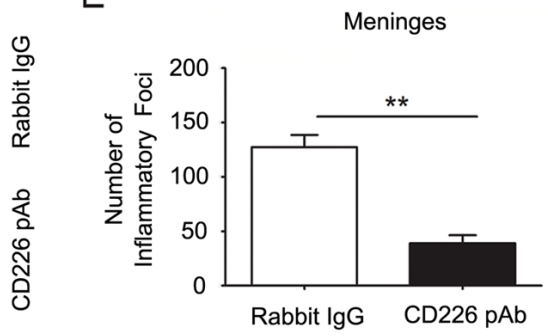

C
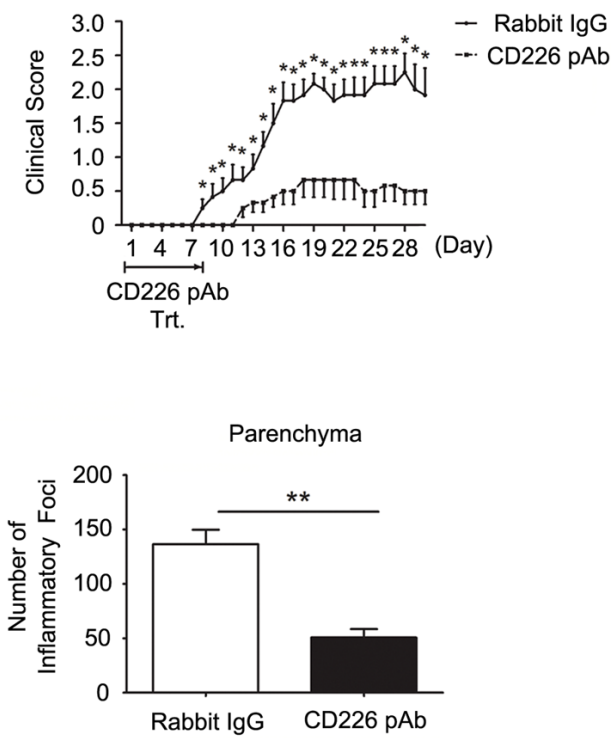

Figure 4: CD226 pAb treatment in vivo reduces EAE susceptibility and severity. A. EAE was elicited in mice with CFA-MOG injection. Mice were administrated with rabbit anti-mouse CD226 pAb (dashed line) or rabbit IgG (solid line) every other day during the first $8 \mathrm{~d}$ of EAE elicitation. The numbers of mice with clinical scores $>1$ were recorded. B. As described in (A), mice were injected with CFA-MOG to elicit EAE and were treated with rabbit anti-mouse CD226 pAb (solid bar) or rabbit IgG (open bar). Median incidence time was calculated using Graphpad Prism 5. C. As described in (A), mice were injected with CFA-MOG to elicit EAE and were treated with rabbit anti-mouse CD226 pAb (dashed line) or rabbit IgG (solid line). D. As described in (A), spinal cords were isolated from mice during the incidence peak (about the $18^{\text {th }} \mathrm{d}$ ) which treated with CD226 pAb and from mice treated with rabbit IgG. Histopathology of representative lumbar spinal cord sections was analyzed by hematoxylin-and-eosin staining. Boxed areas in the left two panels are shown at $\times 20$ magnification in the right two ones respectively. Bars in the left two panels represent $100 \mu \mathrm{m}$; bars in the right two panels represent $5 \mu \mathrm{m}$. E. The inflammatory foci (>10 mononuclear cells) infiltrated in the meninges and parenchyma in the spinal cord sections in (D) were counted. Data are representative of three experiments with 12 mice per group (A-C) or one experiment with at least three to five mice per group (D and E). Error bars denote SEM. $* P<0.05,{ }^{* *} P<0.01$. 
mice compared with their counterparts in the wild type group (Figure 7B). And the mean clinical score of EAE of CD226 knockout mice was significantly decreased since $18 \mathrm{~d}$ after the EAE induction (Figure 7C). In addition, CD226 knockout virtually decreased the production of IFN- $\gamma$ and IL-17 but strongly increased the production of IL-10 with unnoticeable effects on the production of IL-4 (Figure 7D). Furthermore, remarkably reduced infiltration of parenchymal perivascular mononuclear cells was found in the spinal section from CD226 knockout mice as compared with the wild type mice (Figure 7E and 7F). These findings suggested that CD226 has a critical role in mediating $\mathrm{MOG}_{35-55}$-induced EAE at least partially via inhibiting iTreg and promoting Th1/Th17 associated cytokine production.

A
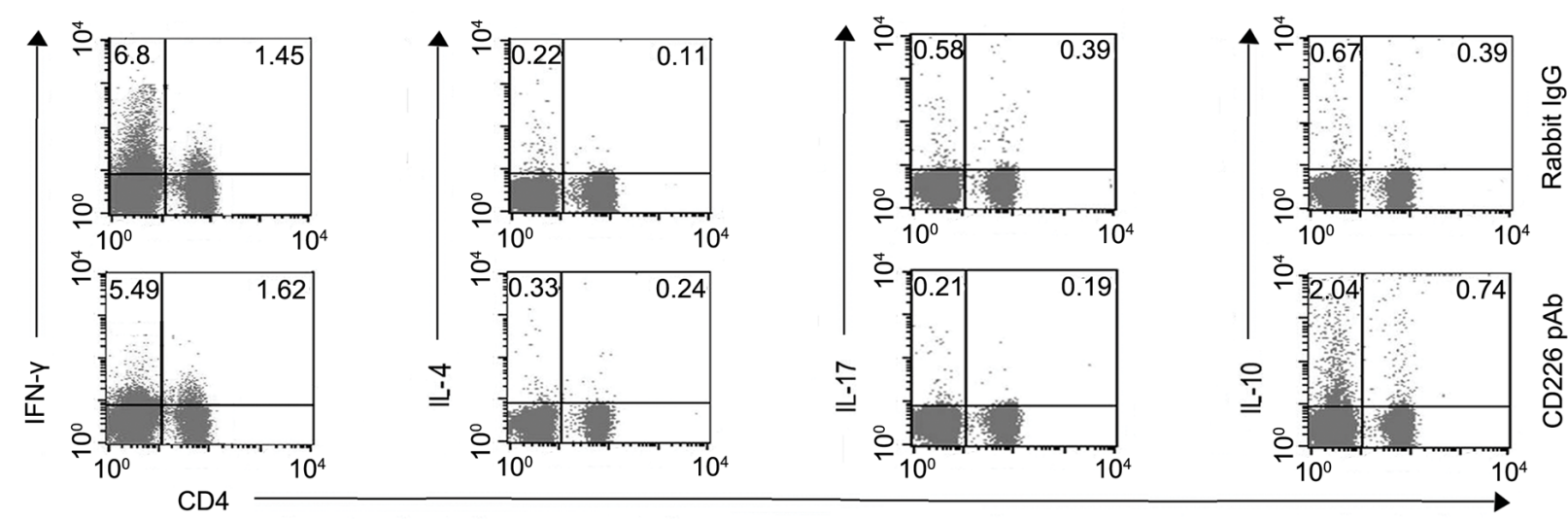

B
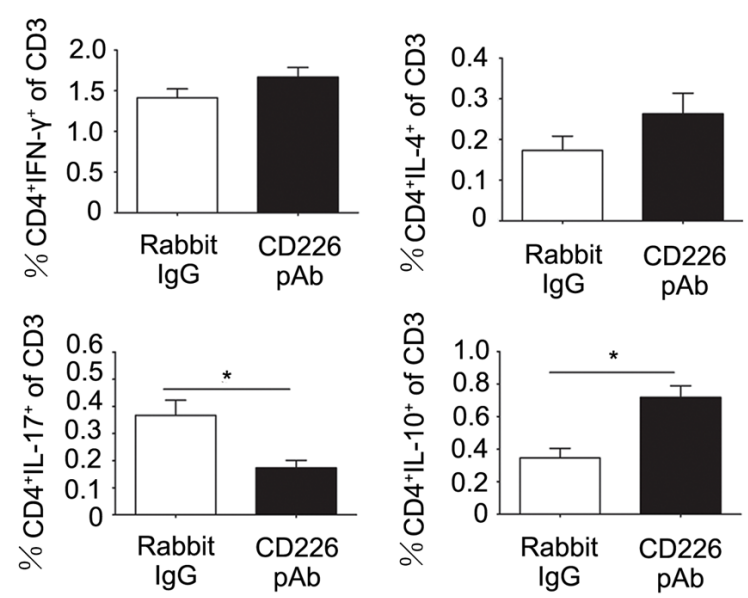
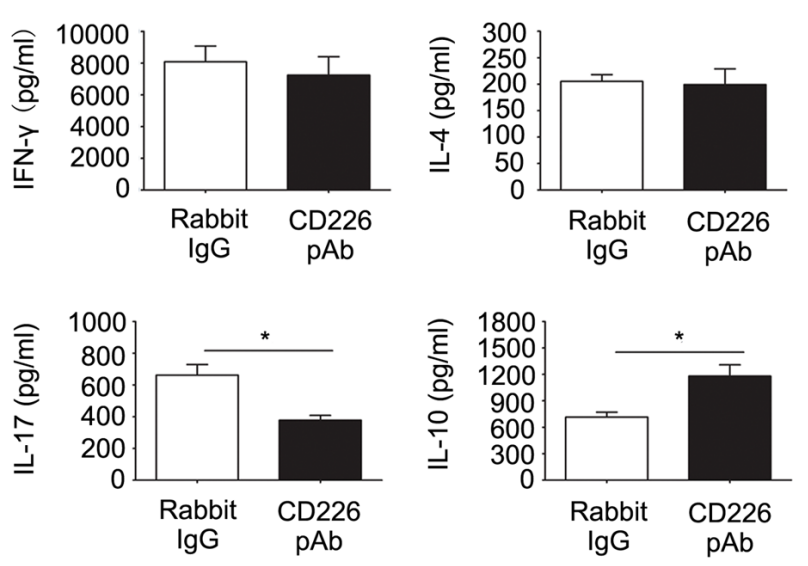

Figure 5: CD226 pAb promotes CD4 ${ }^{+} \mathrm{IL}_{-10} \mathbf{1 0}^{+} \mathrm{T}$ cell differentiation of splenocytes in EAE mice in vivo. A. EAE was elicited in mice with CFA-MOG injection. Mice were also administrated with rabbit anti-mouse CD226 pAb or rabbit IgG every other day during the first $8 \mathrm{~d}$ of EAE elicitation. Splenocytes were isolated from mice with a clinical score of 3 during the incidence peak (about the $18^{\text {th }} \mathrm{d}$ ) which were treated with rabbit IgG and from mice treated with CD226 pAb for the same periods of time. The frequencies of Th subsets were determined by flow cytometry analysis through detecting surface expression of CD4 versus IFN- $\gamma$, IL-4, IL-17 and IL-10 intracellular staining on the isolated splenocytes, stimulated with PMA and ionomycin for $4 \mathrm{~h}$ in the presence of GolgiStop. Cells were stained with LIVE/DEAD Fixable Dead Cell Stain Kit before fixation to allow gating on viable cells. B. The frequencies of Th subsets in the total T cells from experiments described in (A) were compared. C. MACS sorted CD4 ${ }^{+} \mathrm{T}$ cells from the isolated mouse splenocytes as described in (A) were activated under Th1, Th2, Th17 or iTreg conditions for 4d. The production of IFN- $\gamma$, IL-4, IL-17 and IL-10 in the supernatants was quantified by ELISA. Data are representative of one experiment with at least three to five mice per group. Error bars denote SD (B) or $\operatorname{SEM}(\mathrm{C}) . * P<0.05$. 
by promoting IL-10-secreting iTregs and inhibiting Th1/ Th17 generation.

Previous studies showed that Th1, Th17 and Th9 cells each could transfer EAE with similar severity and overlapping but distinct pathological phenotypes [1], and treatment targeting $\mathrm{CD}^{+} \mathrm{T}$ cells differentiation significantly ameliorated EAE [22]. Moreover, suppression of EAE was associated with the decreased frequencies of CD226 expressing $\mathrm{CD}^{+} \mathrm{T}$ cells [23], elevated IL-10 expression and increased number of regulatory $\mathrm{T}$ cells [24]. Thus, we investigated the effect of CD226 ligation on Th subsets and IL-10 secreting $\mathrm{CD}^{+} \mathrm{T}$ cells polarization as well as its contribution to the amelioration of EAE. We claimed that CD226 mAb

A
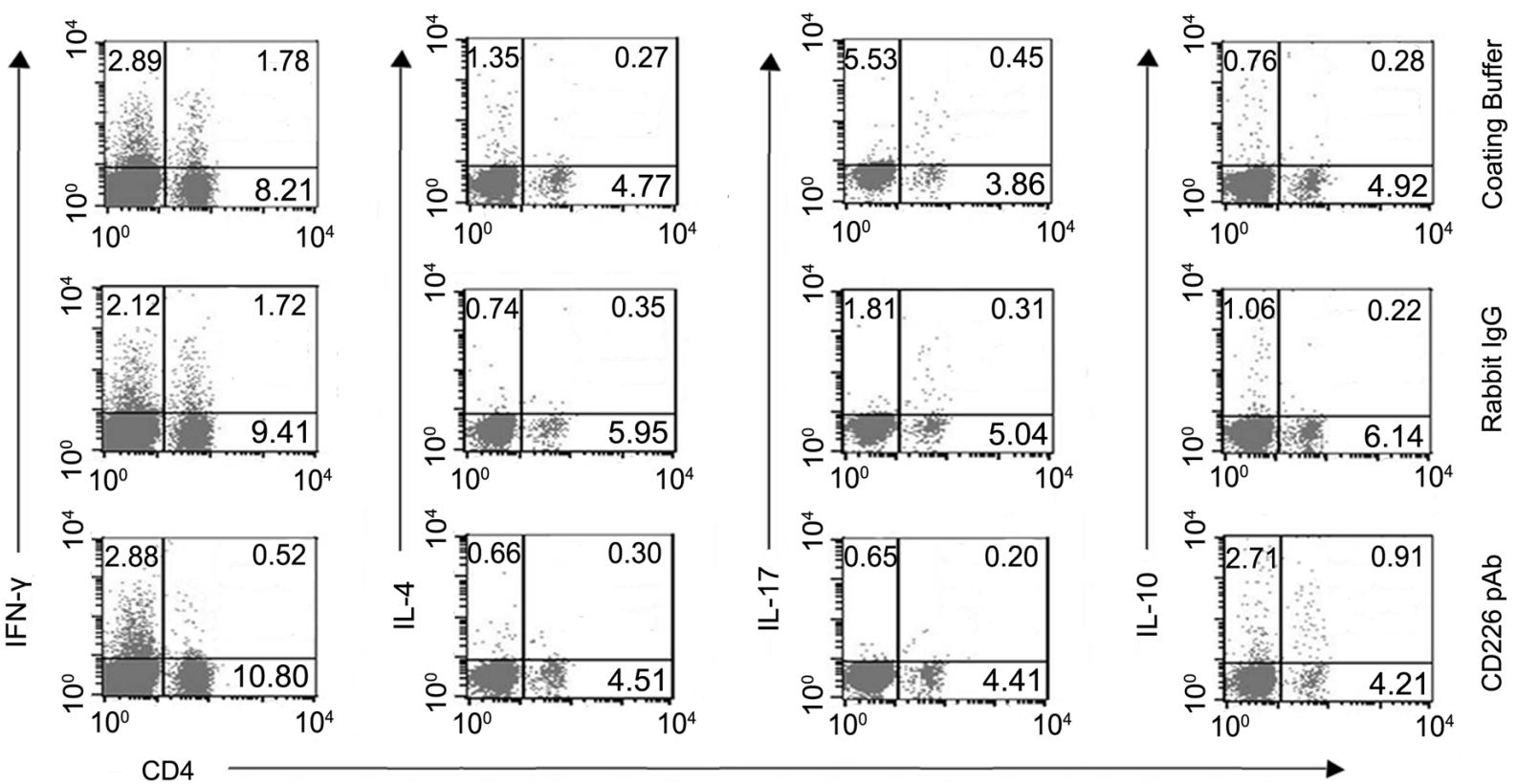

B
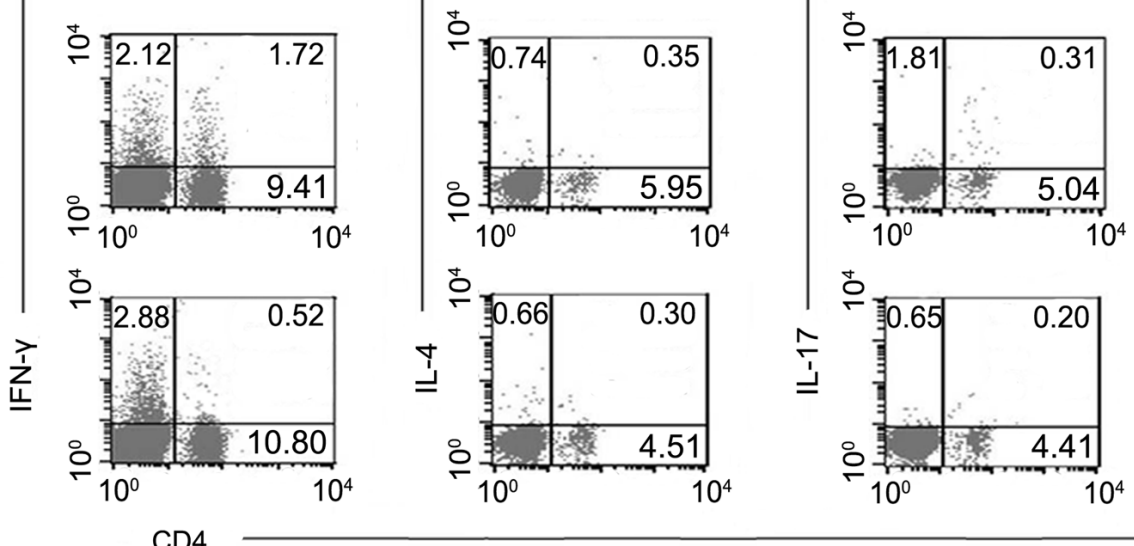

C
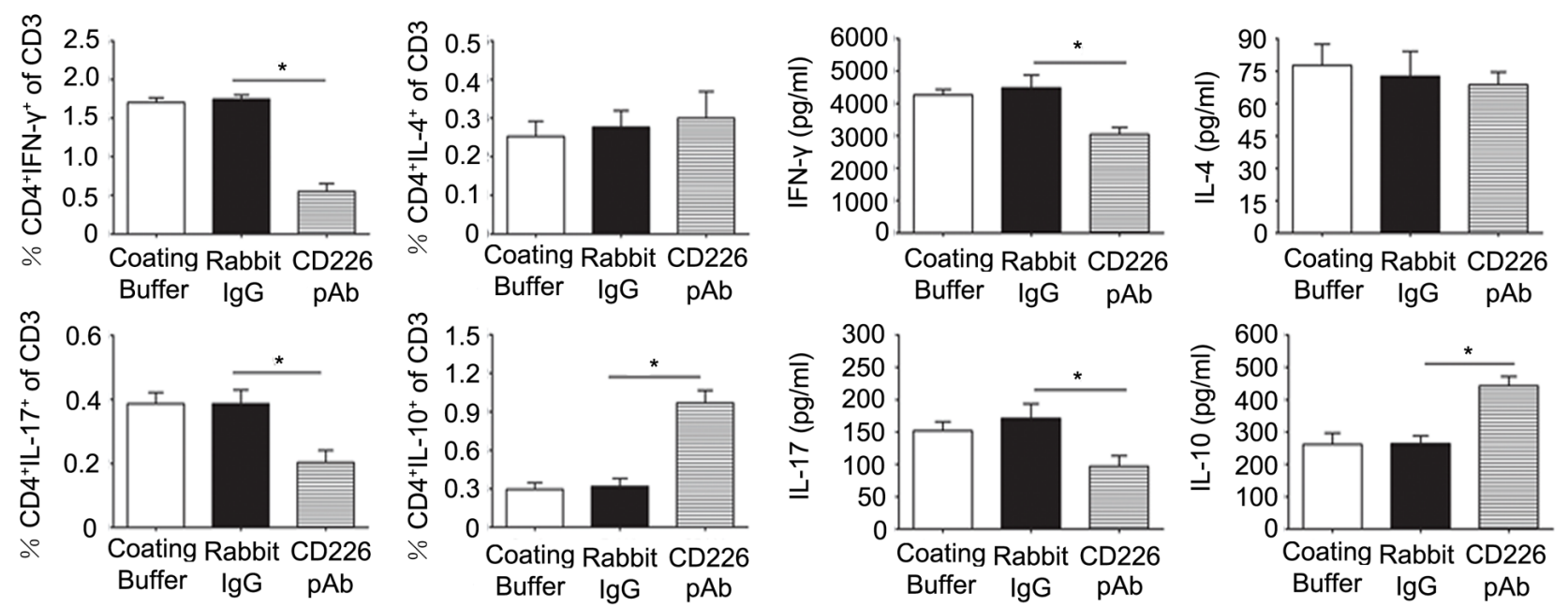

Figure 6: Crosslinked CD226 pAb in vitro induces CD4 ${ }^{+} \mathrm{IL}_{-10}{ }^{+} \mathrm{T}$ cells differentiation of splenocytes in EAE mice. A. EAE was elicited in mice with CFA-MOG injection. Splenocytes were isolated from mice with a clinical score of 3 during the incidence peak (about the $18^{\text {th }} \mathrm{d}$ ) and treated with $\mathrm{MOG}_{35-55}$ and plate bound rabbit anti-mouse CD226 pAb, rabbit IgG (isotype control) or only coating buffer (negative control). On day 3, the frequencies of Th subsets were determined by flow cytometry through surface expression of CD4 versus IFN- $\gamma$, IL-4, IL-17 and IL-10 intracellular staining on the isolated splenocytes, stimulated with PMA and ionomycin for 4h in the presence of GolgiStop. Cells were stained with LIVE/DEAD Fixable Dead Cell Stain Kit before fixation to allow gating on viable cells. B. The frequencies of Th subsets in the total T cells from experiments described in (A) were compared. C. MACS sorted mouse CD4 ${ }^{+} \mathrm{T}$ cells from the isolated splenocytes as described in (A) were treated with $\mathrm{MOG}_{35-55}$ and plate-bound rabbit anti-mouse CD226 pAb, rabbit IgG or only coating buffer under Th1, Th2, Th17 or iTreg conditions for $3 \mathrm{~d}$. The production of IFN- $\gamma$, IL-4, IL-17 and IL-10 in the supernatants was quantified by ELISA. Data are representative of one experiment with at least three to five mice per group. Error bars denote SD (B) or $\operatorname{SEM}(\mathrm{C}) . * P<0.05$. 
LeoA1 played a more predominant role in regulating the $\mathrm{CD}^{+}$Th cells associated cytokines production in MLC system as compared with their counterparts in PBMC system. Furthermore, we think that PBMC is a relatively pure system compared with MLC system. In that system, lymphocytes stay inactivated and always produce a low level of cytokines. Although MLC is a well-known and classical model commonly used in analyzing the HLA antigen compatibility before organ transplantation, the lymphocytes can be activated and proliferate when stimulated by allogeneic antigen on APC and produce a wide range of cytokines in a high level. We found that in both activated T cells and inactivated T cells, CD226 blockage effectively increased the IL-10 production.

Although it has been reported that many immune cells expressed IL-10 including Th and Treg cells, CD8 ${ }^{+}$ $\mathrm{T}$ cells, B cells, dendritic cells (DCs), macrophages, mast cells, natural killer (NK) cells, eosinophils and neutrophils [25-27], here, we found that CD226 mAb LeoA1 significantly stimulated the $\mathrm{CD} 4^{+} \mathrm{IL}-10^{+} \mathrm{T}$ cells differentiation. Consistent with these findings, Ester Lozano et al. reported that blockade of T cell Ig and ITIM domain (TIGIT), a transmembrane glycoprotein which expressed on peripheral memory and regulatory $\mathrm{CD} 4^{+} \mathrm{T}$ cells and NK cells and competing with CD226 for binding to the same ligand CD155, decreased the IL-10 expression derived from human $\mathrm{CD}^{+} \mathrm{T}$ cells [28].

Inspired by the finding that differentially altered $\mathrm{Th}$ subsets associated cytokines were induced by CD226 mAb blockage, we did real-time PCR to confirm its effect on Th and Treg cell differentiation. Considering the purity of RNA isolation, we chose CD3/CD28 system to activate $\mathrm{CD}^{+} \mathrm{T}$ cells instead of the MLC, trying to exclude the disturbance of RNA from the APC (Daudi) and other cells (NK, B cells, DC, macrophages) in MLC system. As for the key transcription factors involved in the differentiation of $\mathrm{CD}^{+} \mathrm{T}$ cells, we found that CD226 mAb LeoA1 decreased T-bet and ROR $\gamma t$ expression and increased Foxp3 expression, skewing cells toward iTreg function while repressing the Th1/Th17 differentiation. In contrast, IL-4 and Gata-3 which are critical in Th2 differentiation were not affected. Contradictorily, it was shown that silencing CD226 expression by lentiviral transduction led to increased $\mathrm{Th} 2$ associated cytokines and transcriptional factors [13]. This discrepancy may be resulted from the fact that cells in the neutralization experiments
A

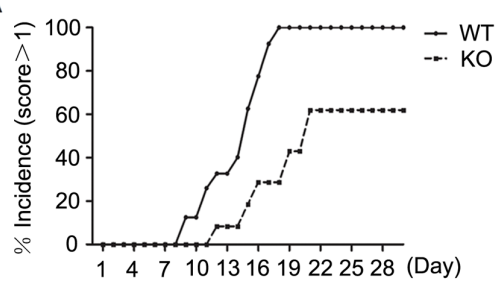

D
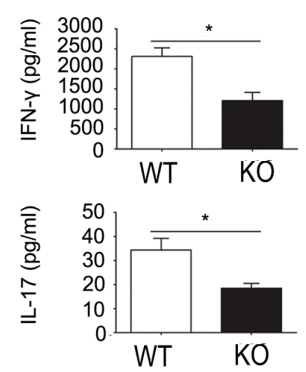

B

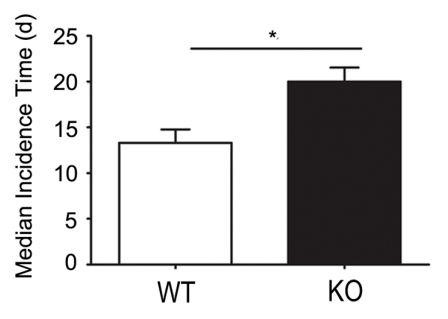

E

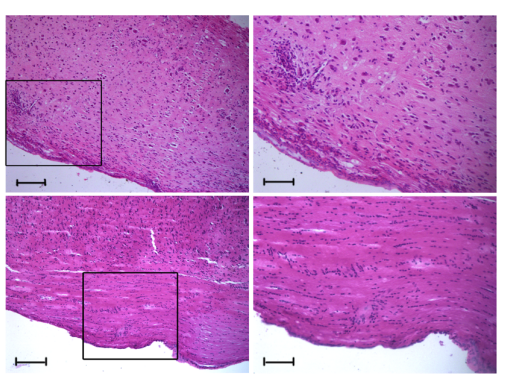

C

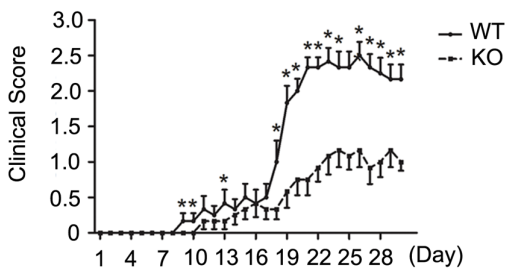

$\mathrm{F}$

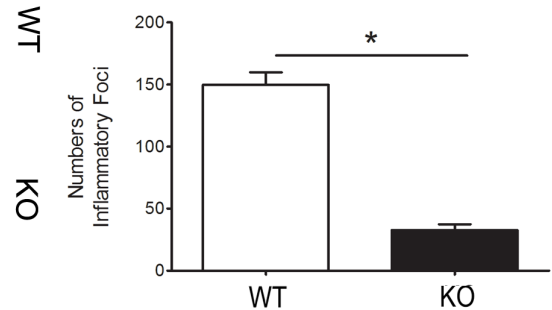

Figure 7: CD226 knockout mice show significantly better outcome of EAE and differentially altered EAE related Th1/ Th17 and iTreg associated cytokines. A. EAE was elicited in CD226- (dashed line) and wild type (solid line) mice with CFA-MOG injection. The numbers of mice with clinical scores $>1$ were recorded. B. As described in (A), CD226- (solid bar) and wild type (open bar) mice were injected with CFA-MOG to elicit EAE. Median incidence time was calculated using Graphpad Prism 5. C. As described in (A), CD226 knockout (dashed line) and wild type (solid line) mice were injected with CFA-MOG to elicit EAE. Clinical scores of EAE were recorded every day thereafter. D. As described in (A), CD226 knockout (solid bar) and wild type (open bar) mice were injected with CFAMOG to elicit EAE. Eye ball venous blood from mice during the incidence peak (about the $18^{\text {th }} \mathrm{d}$ ) were collected. IFN- $\gamma$, IL-4, IL-17, and IL-10 expression levels were determined by ELISA. E. As described in (A), spinal cords were isolated from CD226 knockout or WT mice induced with EAE at $18^{\text {th }} \mathrm{d}$ to $21^{\text {st }}$ d. Histopathology of representative lumbar spinal cord sections was analyzed by hematoxylin-and-eosin staining. Boxed areas in the left two panels are shown at $\times 5$ magnification in the right two ones respectively. Bars in the left two panels represent $25 \mu \mathrm{m}$; bars in the right two panels represent $5 \mu \mathrm{m}$. F. The inflammatory foci ( $>10$ mononuclear cells) infiltrated in the spinal cord sections in (E) were counted. Data are representative of three experiments with 12 mice per group (A-D) or one experiment with at least three to five mice per group (E and F). Error bars denote SEM. $* P<0.05$. 
were incubated under Th2-polarizing conditions, thus, expressed lower levels of CD226, inhibiting part of the effects displayed by LeoA1, which has been proved by the differential expression levels of CD226 in human CD4 ${ }^{+}$ Th subsets under respective Th-polarizing conditions [13]. Further studies should be focused on the key receptors and transcriptional factors in the differentiation process of Th subsets and iTregs, such as TGF- $\beta$ receptor II and STAT5, which were closely associated with generation and stability maintenance of iTreg [29], as well as IL-10 receptor I and STAT3, which is critical to IL-10 associated biological functions [30]. Considering that the Foxp3 gene expression was also markedly elevated, and the $\mathrm{CD}^{+} \mathrm{T}$ cells were isolated from PBMC then cultured under iTreg differentiation condition with $\mathrm{CD} 3 / \mathrm{CD} 28 \mathrm{Ab}$ rather than generated from thymus, it is reasonable to believe that the upregulated IL-10 secreting $\mathrm{CD}^{+} \mathrm{T}$ cells were iTregs instead of nTregs.

Previous studies have shown that anti-CD226 treatment delayed the onset and reduced the severity of Th1-mediated EAE, the mechanism was supposed to be the cell death of Th1 cells or the inhibited migration of inflammatory cells (T cells or macrophages) to CNS[12]. Moreover, loss of the inhibitory molecule TIGIT which competing for the same ligand with CD226, resulted in hyperproliferative $\mathrm{T}$ cell responses and increased susceptibility to autoimmunity [31]. Consistently, we found in this study that CD226 pAb treatment effectively reduced the onset and severity of EAE in mice. More importantly, experiments with CD226 knockout mice further proved the protective effects of CD226 ligation, offering solid evidence of the positive effects of CD226 on the pathogenesis of autoimmune diseases manifested here by EAE. Lymphocytes of EAE mice exposed to CD226 $\mathrm{pAb}$ further indicated the reciprocally regulated Th1/Th17 and iTreg differentiation by CD226 ligation except the unchanged IFN- $\gamma$ producing Th1 cell proportion and the IFN- $\gamma$ production in the in vivo experiment. As for this unexpected result, we postulated it might be due to the different action modes of CD226 pAb when administrated in vivo or ex vivo.

Additionally, we proved that the significantly elevated IL-10 production may contribute to the amelioration of EAE mediated by CD226 pAb treatment or in CD226 knockout mice. Similar to our results, it was reported that immunoregulatory cytokines, including IL-10, inhibited the development of EAE [32]. IL-10 suppresses effector $\mathrm{T}$ cell responses and limits inflammation. Furthermore, IL-10-deficient mice develop more severe EAE than wild-type (WT) mice. However, despite the well-established immunoregulatory effects and functions of ectopically expressed IL-10, efficacy of pharmacologically administered IL-10 in EAE might vary with timing and mode of administration, and could even exacerbate disease [33].

In conclusion, we demonstrated that CD226 ligation inhibited the Th1/Th17 differentiation and promoted iTreg differentiation of $\mathrm{CD}^{+} \mathrm{T}$ cells. In addition, CD226 plays an important role in maintaining the pathological process and mediating clinical symptoms of EAE via stimulating Th1/Th17 differentiation of $\mathrm{CD}^{+} \mathrm{T}$ cells. More importantly, we revealed for the first time that promoting IL-10 production and the CD $4^{+} \mathrm{IL}-10^{+} \mathrm{T}$ cells may be a novel mechanism involved in the amelioration of EAE exhibited by CD226 ligation, thus indicating that blocking CD226 molecule may be a novel target for the therapeutic intervention and treatment of MS by enhancing the expression of IL-10 and iTreg differentiation.

\section{MATERIALS AND METHODS}

\section{Mice}

CD226 ${ }^{-/}$mice in C57BL/6 background were kindly offered by Professor Marco Colonna. C57BL/6 mice of 8 weeks were purchased from Yison BIO (Shanghai) and all animals were maintained under pathogen-free conditions at Experimental Animals Center of Fourth Military Medical University. The Institutional Review Board (IRB) of the Fourth Military Medical University approved the experiments (permit number XJYYLL-2014433) which were performed according to the relevant guidelines and regulations.

\section{Reagents}

Lymphocyte separation medium and FBS were respectively purchased from Millipore and Gibco. Abs to CD226 were generated as previously described $[34,35]$. All other reagents were purchased from Sigma-Aldrich (St Louis, MO) except that myelin oligodendrocyte glycoprotein $\left(\mathrm{MOG}_{35-55}\right)$ was purchased from Difco, Detroit, MI. Antibodies for flow cytometry were listed in Table 1.

\section{MLC and PBMC culture systems}

Human PBMC (responding cells) were purified by density gradient centrifugation method [36] and cultured with or without x-irradiated (3000 rads) Daudi (stimulating cells) in complete media consisting of RPMI 1640 with 10\% FBS, 2 mM L-glutamine, 10 mM Hepes, and $1 \times$ pen $/$ strep/glutamine solution (Sigma-Aldrich). The cell concentrations were $1 \times 10^{5}$ stimulating and $1 \times 10^{6}$ responding cells, that is $1 \mathrm{ml} /$ well in 24-well U-bottom plate (Costar, Cambridge, MA). The plate was incubated at $37^{\circ} \mathrm{C}$ in the presence of $5 \% \mathrm{CO}_{2}$ for the indicated periods of time with the supernatants or cells to be tested. 
Table 1: Information for the antibodies utilized in flow cytometry assay

\begin{tabular}{|c|c|c|c|c|}
\hline Target molecule & Clone & Reactivity & Fluorescence & Corporation \\
\hline IL-10 & JES3-9D7 & Human & $\mathrm{PE}$ & BioLegend \\
\hline CD3 & OKT3 & Human & APC & BioLegend \\
\hline CD4 & OKT4 & Human & PerCP/Cy5.5 & BioLegend \\
\hline $\begin{array}{l}\text { CD11c } \\
\text { CD14 } \\
\text { CD16 } \\
\text { CD19 } \\
\text { CD56 } \\
\text { HLA-DR }\end{array}$ & $\begin{array}{l}\text { Bu15 } \\
\text { HCD14 } \\
\text { 3G8 } \\
\text { HIB19 } \\
\text { HCD56 } \\
\text { L243 }\end{array}$ & $\begin{array}{l}\text { Human } \\
\text { Human } \\
\text { Human } \\
\text { Human } \\
\text { Human } \\
\text { Human }\end{array}$ & $\begin{array}{l}\text { PerCP/Cy5.5 } \\
\text { FITC } \\
\text { FITC } \\
\text { PerCP/Cy5.5 } \\
\text { APC } \\
\text { FITC }\end{array}$ & $\begin{array}{l}\text { BioLegend } \\
\text { BioLegend } \\
\text { BioLegend } \\
\text { BioLegend } \\
\text { BioLegend } \\
\text { BioLegend }\end{array}$ \\
\hline CD4 & RM4-4 & Mouse & PerCP/Cy5.5 & BioLegend \\
\hline IL-4 & 11B11 & Mouse & $\mathrm{PE}$ & BioLegend \\
\hline IL-10 & JES5-16E3 & Mouse & $\overline{\mathrm{PE}}$ & BioLegend \\
\hline IL-17 & FN50 & Mouse & $\mathrm{PE}$ & BioLegend \\
\hline IFN- $\gamma$ & XMG1.2 & Mouse & $\mathrm{PE}$ & BioLegend \\
\hline Rat IgG1, $\kappa$ & RTK2071 & Rat & $\mathrm{PE}$ & BioLegend \\
\hline Rat IgG2b, $\kappa$ & RTK4530 & Rat & APC & BioLegend \\
\hline Rat IgG2b, $\kappa$ & RTK4530 & Rat & PerCP/Cy5.5 & BioLegend \\
\hline Mouse IgG2b, $\kappa$ & MPC-11 & Mouse & PerCP/Cy5.5 & BioLegend \\
\hline Mouse IgG2a, $\kappa$ & MOPC-173 & Mouse & APC & BioLegend \\
\hline
\end{tabular}

\section{Measurement of cytokine production in culture supernatants and serum}

Culture supernatants were harvested at the indicated time point, serum of mice eye ball venous blood was also collected. IFN- $\gamma$, TNF- $\alpha$, IL-2, IL-12, IL-4, IL-17, IL-23 and IL-10 expression levels were measured using the respective ELISA kits (R\&D Systems; eBioscience) following the manufacturer's instructions. Absorbance was measured at $450 \mathrm{~nm}$ using a Benchmark microplate reader (Bio-Rad).

\section{Intracellular cytokine staining}

Before detection of intracellular cytokine production, human PBMC or isolated mice splenocytes were restimulated with PMA $(50 \mathrm{ng} / \mathrm{ml})$ plus ionomycin $(500 \mathrm{ng} / \mathrm{ml})$ for $4 \mathrm{~h}$ in the presence of Brefeldin A (GolgiStop; BD Biosciences). Staining with LIVE/ DEAD Fixable Dead Cell Stain Kit (Molecular Probes) was performed before fixation to allow gating on viable cells. Cells were then blocked for 15 mins and stained with antibodies targeting specific surface markers for different lymphocytes (APC anti-CD3, PerCP/Cy5.5 anti-CD4/ PerCP/Cy5.5 anti-CD19/ FITC anti-CD16, APC antiCD56/ FITC anti-HLA-DR, PerCP/Cy5.5 anti-CD11c/ FITC anti-CD14) at $4{ }^{\circ} \mathrm{C}$ for 30 mins. After fixation and permeabilization with Fixation and Permeabilization solution (BD Biosciences) for 20 mins, cells were stained with PE anti-IFN- $\gamma$, PE anti-IL-4, PE anti-IL-17, PE antiIL-10 or PE Rat IgG1, $\kappa$ (BioLegend) $4{ }^{\circ} \mathrm{C}$ for 30 mins respectively and then submitted to flow cytometry analysis
(FACS Calibur; BD Biosciences).

\section{In vitro $\mathrm{T}$ cell differentiation assays}

Human $\mathrm{CD}^{+} \mathrm{T}$ cells and mice $\mathrm{CD}^{+} \mathrm{T}$ cells were purified using negative selection $\left(\mathrm{CD}^{+} \mathrm{T}\right.$ Cell Isolation Kit, human; $\mathrm{CD}^{+} \mathrm{T}$ cell Isolation kit, mouse; Miltenyi Biotec, Auburn, CA) respectively. Purified human and mice $\mathrm{CD}^{+} \mathrm{T}$ cells were stimulated in the presence of anti-CD3 (5 $\mu \mathrm{g} / \mathrm{ml}, \mathrm{UCHT} 1 ; 1 \mu \mathrm{g} / \mathrm{ml}, 145-2 \mathrm{C} 11)$ and anti-CD28 (1 $\mu \mathrm{g} / \mathrm{ml}, \mathrm{CD} 28.2 ; 1 \mu \mathrm{g} / \mathrm{ml}, 37.51)$ (BD Biosciences) for $3 \mathrm{~d}$ under the following conditions-For human $\mathrm{CD}^{+}$T cells: Th1: rhIL-12 (10 ng/ml; Peprotech, Rocky Hill, NJ); Th2: rhIL-4 (25 ng/ml; Peprotech); Th17: TGF- $\beta$ (5 ng/ml; Peprotech), IL-1 $\beta$, IL-21 and IL-23 (all $25 \mathrm{ng} / \mathrm{ml}$; Peprotech); Treg: $1 \mathrm{ng} / \mathrm{ml} \mathrm{rhTGF}-\beta$ and $2 \mathrm{ng} /$ $\mathrm{ml}$ rhIL-2 (Peprotech). Recombinant human IL-2 was bought through ACRO Biosystems and was used at 10 $\mathrm{U} / \mathrm{ml}$, except under Treg $(2 \mathrm{ng} / \mathrm{ml})$ and Th17 conditions. For mice $\mathrm{CD}^{+}{ }^{+} \mathrm{T}$ cells: Th1: $40 \mathrm{ng} / \mathrm{ml}$ rIL-12 (Peprotech) and $40 \mu \mathrm{g} / \mathrm{ml}$ anti-IL-4 (R \& D); Th2: $40 \mathrm{ng} / \mathrm{ml} \mathrm{rIL-4}$ (Peprotech) and $10 \mu \mathrm{g} / \mathrm{ml}$ anti-IFN- $\gamma$ (R \& D); Th17: 1 ng/ml rTGF- $\beta$ and 40 ng/ml rIL-6 (both Peprotech), 40 $\mu \mathrm{g} / \mathrm{ml}$ anti-IL-4 and $10 \mu \mathrm{g} / \mathrm{ml}$ anti-IFN- $\gamma$ (both R \& D); Treg: $1 \mathrm{ng} / \mathrm{ml}$ rTGF- $\beta$ and $2 \mathrm{ng} / \mathrm{ml}$ rIL-2 (both Peprotech).

\section{Real-time quantitative RT-PCR}

Purified human CD4 ${ }^{+} \mathrm{T}$ cells were cultured in Th1, Th2, Th17 or iTreg conditions in the presence of antiCD3 and anti-CD28 for 3d before total RNA was isolated with TRIZOL (Invitrogen, Carlsbad, CA). cDNA was 
synthesized with PrimeScript ${ }^{\mathrm{TM}}$ RT Master Mix (Takara). Real-time quantitative polymerase chain reaction (PCR) was performed using 7500 Fast Real-Time PCR System (Applied Biosystems, Forest City, CA) according to the manufacturer's instructions with SYBR ${ }^{\circledR}$ Premix Ex $T_{a q^{\mathrm{TM}}}$ II (Takara). The gene-specific primer sequences were displayed as in Supplemental Figure 2. Relative expression levels of genes were normalized within each sample to the expression of GAPDH. Expression of genes was determined relative to Hprt by the $\Delta \Delta \mathrm{CT}$ method.

\section{EAE induction, evaluation and administration with CD226 pAb}

EAE was induced in female C57BL/6 mice. 24 Mice were injected subcutaneously with

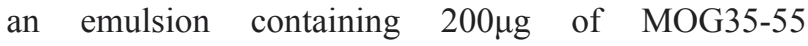
(MEVGWYRSPFSRVVHLYRNGK) and complete freund's adjuvant (CFA) supplemented with $200 \mu \mathrm{g}$ of H37RA in the posterior right and left flank; Mice were also injected with $75 \mathrm{ng}$ and $200 \mathrm{ng}$ PTx intraperitoneally on day 0 and 2 relative to immunization. One week later, all mice were similarly injected at 2 sites on the right and left flank anterior of the initial injection sites $\left(2 \times \mathrm{MOG}_{35-55}+\mathrm{CFA}\right)$. The mice were assessed for signs of EAE according to the following scale: 0 , normal; 1 , limp tail or mild hind-limb weakness; 2 , moderate hind-limb weakness or mild ataxia; 3, moderately severe hind-limb weakness; 4, severe hind-limb weakness or mild fore-limb weakness or moderate ataxia; 5, paraplegia with no more than moderate fore-limb weakness; and 6, paraplegia with severe fore-limb weakness or severe ataxia or moribund condition. Rabbit anti-mouse CD226 pAb or rabbit IgG was injected i.p. at a dose of $5 \mathrm{mg} / \mathrm{kg}$ every other day from day 0 to day 8 .

\section{Histopathology analysis}

Mice induced with EAE at $18^{\text {th }} \mathrm{d}$ to $21^{\text {st }} \mathrm{d}$ were sacrificed. Spinal cords were harvested and fixed in $10 \%$ neutral-buffered formalin and processed routinely for paraffin embedment. Slides were stained with hematoxylin-and-eosin and the images were captured by Nikon Eclipse E200 microscopy (Melville, NY). Histological lesion was evaluated by counting the inflammatory foci ( $>10$ mononuclear cells) in the meninges and parenchyma in a blinded fashion in that the pathologist was unaware of the clinical status.

\section{Statistical analysis}

Real time RT-PCR, ELISA, and survival analysis data were analyzed with GraphPad Prism version 5.0 (GraphPad Software, San Diego, CA). Flow cytometry data were analyzed with FlowJo software (TreeStar, Ashland, OR). Data representing the means \pm standard deviation (SD) or means \pm standard error $(\mathrm{SE})$ of the results were compared by either the two-tailed Student t test (two groups) or ANOVA (multiple groups), with a posthoc Tukey test to determine significance. All analyses were performed using GraphPad Prism version 5.0. A $p$ value $\leq 0.05$ was considered statistically significant.

\section{ACKNOWLEDGMENTS}

We thank Professor Marco Colonna for generously providing CD226-- mice. We acknowledge Dr. Donglin Wang for generously raising and identifying murine CD226 pAb.

\section{CONFLICTS OF INTEREST}

The authors have no financial conflicts of interest.

\section{GRANT SUPPORTS}

This work was supported by the National Natural Science Foundation of China (81571531 and 91442108).

\section{REFERENCES}

1. Jager A, Dardalhon V, Sobel RA, Bettelli E and Kuchroo VK. Th1, Th17, and Th9 effector cells induce experimental autoimmune encephalomyelitis with different pathological phenotypes. J Immunol. 2009; 183:7169-7177.

2. Merrill JE, Kono DH, Clayton J, Ando DG, Hinton DR and Hofman FM. Inflammatory leukocytes and cytokines in the peptide-induced disease of experimental allergic encephalomyelitis in SJL and B10.PL mice. Proceedings of the National Academy of Sciences of the United States of America. 1992; 89:574-578.

3. Zhao YG, Wang Y, Guo Z, Gu AD, Dan HC, Baldwin AS, Hao W and Wan YY. Dihydroartemisinin ameliorates inflammatory disease by its reciprocal effects on Th and regulatory $\mathrm{T}$ cell function via modulating the mammalian target of rapamycin pathway. J Immunol. 2012; 189:44174425.

4. Chard L, Maniati E, Wang P, Zhang Z, Gao D, Wang J, Cao F, Ahmed J, Khouri ME, Hughes J, Wang S, Li X, Denes B, Fodor I, Hagemann T, Lemoine NR, et al. A Vaccinia virus armed with interleukin-10 is a promising therapeutic agent for treatment of murine pancreatic cancer. Clinical cancer research. 2015; 21:405-16.

5. Hofmann SR, Rosen-Wolff A, Tsokos GC and Hedrich CM. Biological properties and regulation of IL-10 related cytokines and their contribution to autoimmune disease and tissue injury. Clinical immunology. 2012; 143:116-127.

6. Croxford JL, Feldmann M, Chernajovsky Y and Baker D. Different therapeutic outcomes in experimental allergic 
encephalomyelitis dependent upon the mode of delivery of IL-10: a comparison of the effects of protein, adenoviral or retroviral IL-10 delivery into the central nervous system. J Immunol. 2001; 166:4124-4130.

7. Liu X, Alli R, Steeves M, Nguyen P, Vogel P and Geiger TL. The T cell response to IL-10 alters cellular dynamics and paradoxically promotes central nervous system autoimmunity. J Immunol. 2012; 189:669-678.

8. Blazevski J, Petkovic F, Momcilovic M, Jevtic B, Miljkovic D and Mostarica Stojkovic M. High interleukin-10 expression within the central nervous system may be important for initiation of recovery of Dark Agouti rats from experimental autoimmune encephalomyelitis. Immunobiology. 2013; 218:1192-1199.

9. Bettelli E, Das MP, Howard ED, Weiner HL, Sobel RA and Kuchroo VK. IL-10 is critical in the regulation of autoimmune encephalomyelitis as demonstrated by studies of IL-10- and IL-4-deficient and transgenic mice. Journal of immunology. 1998; 161:3299-3306.

10. de Andrade LF, Smyth MJ and Martinet L. DNAM-1 control of natural killer cells functions through nectin and nectin-like proteins. Immunology and cell biology. 2014; 92:237-244.

11. Hou S, Ge K, Zheng X, Wei H, Sun R and Tian Z. CD226 protein is involved in immune synapse formation and triggers Natural Killer (NK) cell activation via its first extracellular domain. The Journal of biological chemistry. 2014; 289:6969-6977.

12. Dardalhon V, Schubart AS, Reddy J, Meyers JH, Monney L, Sabatos CA, Ahuja R, Nguyen K, Freeman GJ, Greenfield EA, Sobel RA and Kuchroo VK. CD226 is specifically expressed on the surface of Th1 cells and regulates their expansion and effector functions. Journal of immunology. 2005; 175:1558-1565.

13. Lozano E, Joller N, Cao Y, Kuchroo VK and Hafler DA. The CD226/CD155 interaction regulates the proinflammatory (Th1/Th17)/anti-inflammatory (Th2) balance in humans. J Immunol. 2013; 191:3673-3680.

14. de Waal Malefyt R, Abrams J, Bennett B, Figdor CG and de Vries JE. Interleukin 10(IL-10) inhibits cytokine synthesis by human monocytes: an autoregulatory role of IL-10 produced by monocytes. J Exp Med. 1991; 174:1209-1220.

15. de Waal Malefyt R, Yssel H and de Vries JE. Direct effects of IL-10 on subsets of human CD4+ T cell clones and resting $\mathrm{T}$ cells. Specific inhibition of IL-2 production and proliferation. J Immunol. 1993; 150:4754-4765.

16. Chaudhry A, Samstein RM, Treuting P, Liang Y, Pils MC, Heinrich JM, Jack RS, Wunderlich FT, Bruning JC, Muller $\mathrm{W}$ and Rudensky AY. Interleukin-10 signaling in regulatory $\mathrm{T}$ cells is required for suppression of Th17 cell-mediated inflammation. Immunity. 2011; 34:566-578.

17. Murai M, Turovskaya O, Kim G, Madan R, Karp CL, Cheroutre $\mathrm{H}$ and Kronenberg $\mathrm{M}$. Interleukin 10 acts on regulatory $\mathrm{T}$ cells to maintain expression of the transcription factor Foxp3 and suppressive function in mice with colitis. Nat Immunol. 2009; 10:1178-1184.

18. MacKenzie KF, Pattison MJ and Arthur JSC. Transcriptional Regulation of IL-10 and Its Cell-Specific Role In Vivo. Crit Rev Immunol. 2014; 34:315-345.

19. Burchill MA, Yang J, Vogtenhuber C, Blazar BR and Farrar MA. IL-2 receptor beta-dependent STAT5 activation is required for the development of Foxp3+ regulatory T cells. J Immunol. 2007; 178:280-290.

20. Xu L, Kitani A, Stuelten C, McGrady G, Fuss I and Strober W. Positive and negative transcriptional regulation of the Foxp3 gene is mediated by access and binding of the Smad3 protein to enhancer I. Immunity. 2010; 33:313-325.

21. Laurence A, Amarnath S, Mariotti J, Kim YC, Foley J, Eckhaus M, O'Shea JJ and Fowler DH. STAT3 transcription factor promotes instability of nTreg cells and limits generation of iTreg cells during acute murine graftversus-host disease. Immunity. 2012; 37:209-222.

22. Tullius SG, Biefer HR, Li S, Trachtenberg AJ, Edtinger K, Quante M, Krenzien F, Uehara H, Yang X, Kissick HT, Kuo WP, Ghiran I, de la Fuente MA, Arredouani MS, Camacho V, Tigges JC, et al. NAD+ protects against EAE by regulating CD4+ T-cell differentiation. Nature communications. 2014; 5:5101.

23. Sinha S, Miller LM, Subramanian S, Burrows GG, Vandenbark AA and Offner H. RTL551 treatment of EAE reduces CD226 and T-bet+ CD4 T cells in periphery and prevents infiltration of T-bet+ IL-17, IFN-gamma producing T cells into CNS. PloS one. 2011; 6:e21868.

24. Dai H, Ciric B, Zhang GX and Rostami A. Interleukin-10 plays a crucial role in suppression of experimental autoimmune encephalomyelitis by Bowman-Birk inhibitor. Journal of neuroimmunology. 2012; 245:1-7.

25. Moore KW, de Waal Malefyt R, Coffman RL and O'Garra A. Interleukin-10 and the interleukin-10 receptor. Annual review of immunology. 2001; 19:683-765.

26. O'Garra A and Vieira P. T(H)1 cells control themselves by producing interleukin-10. Nature reviews Immunology. 2007; 7:425-428.

27. Maynard CL and Weaver CT. Diversity in the contribution of interleukin-10 to T-cell-mediated immune regulation. Immunological reviews. 2008; 226:219-233.

28. Lozano E, Dominguez-Villar M, Kuchroo V and Hafler DA. The TIGIT/CD226 axis regulates human T cell function. J Immunol. 2012; 188:3869-3875.

29. Betts BC, Veerapathran A, Pidala J, Yu XZ and Anasetti C. STAT5 polarization promotes iTregs and suppresses human T-cell alloresponses while preserving CTL capacity. Journal of leukocyte biology. 2014; 95:205-213.

30. Ding Y, Qin L, Zamarin D, Kotenko SV, Pestka S, Moore KW and Bromberg JS. Differential IL-10R1 expression plays a critical role in IL-10-mediated immune regulation. J Immunol. 2001; 167:6884-6892. 
31. Joller N, Hafler JP, Brynedal B, Kassam N, Spoerl S, Levin $\mathrm{SD}$, Sharpe AH and Kuchroo VK. Cutting edge: TIGIT has T cell-intrinsic inhibitory functions. J Immunol. 2011; 186:1338-1342.

32. Bettelli E, Nicholson LB and Kuchroo VK. IL-10, a key effector regulatory cytokine in experimental autoimmune encephalomyelitis. Journal of autoimmunity. 2003; 20:265267.

33. Cua DJ, Hutchins B, LaFace DM, Stohlman SA and Coffman RL. Central nervous system expression of IL-10 inhibits autoimmune encephalomyelitis. J Immunol. 2001; 166:602-608.
34. Wang D, Zhang X, Xu X, Song C, Xu Z and Jin B. Generation of rat monoclonal antibodies against murine PTA1/CD226. Hybridoma (Larchmt). 2007; 26:73-77.

35. Jia W, Liu XS, Zhu Y, Li Q, Han WN, Zhang Y, Zhang JS, Yang K, Zhang XH and Jin BQ. Preparation and characterization of mabs against different epitopes of CD226 (PTA1). Hybridoma. 2000; 19:489-494.

36. Fuss IJ, Kanof ME, Smith PD and Zola H. Isolation of whole mononuclear cells from peripheral blood and cord blood. Current protocols in immunology / edited by John E Coligan [et al]. 2009; Chapter 7:Unit7 1. 